\title{
Long-term variation in soil temperature of the Mojave Desert, southwestern USA
}

\author{
Yanying Bai ${ }^{1,2}$, Thomas A. Scott ${ }^{2}$, Weiping Chen ${ }^{3, *}$, Richard A. Minnich ${ }^{2}$, \\ Andrew C. Chang ${ }^{4}$ \\ ${ }^{1}$ Institute of Geographic Sciences and Natural Resources Research, Chinese Academy of Sciences, Beijing 100101, PR China \\ ${ }^{2}$ Department of Earth Sciences, University of California, Riverside, California 92521, USA \\ ${ }^{3}$ State Key Laboratory for Urban and Regional Ecology, Center for Eco-Environmental Sciences, \\ Chinese Academy of Sciences, Beijing 100085, PR China \\ ${ }^{4}$ Department of Environmental Sciences, University of California, Riverside, California 92521, USA
}

\begin{abstract}
Soil temperature, an important climatic variable, regulates ecosystem processes, especially those occurring below ground, and is an indicator on how changing global climate affects regional ecosystems. We examined the correlation between the mean annual soil temperature (MAST) and climatic factors in the Mojave Desert and built an empirical model to predict changes of MAST from mean annual air temperature (MAAT) and annual precipitation (P), such that MAST $\left({ }^{\circ} \mathrm{C}\right)=6.84+0.925 \times \operatorname{MAAT}\left({ }^{\circ} \mathrm{C}\right)-0.0031 \times \mathrm{P}\left(\mathrm{mm} \mathrm{yr}^{-1}\right)$. Based on climate records from 1904 to 2008 , the mean annual air temperature in the Mojave Desert has risen by approximately $2^{\circ} \mathrm{C}$. The annual precipitation pattern showed distinctive wet and dry cycles. However, the outcomes of linear regression showed that the annual precipitation did not significantly change over the time. We back-casted the mean annual soil temperature of the past century, which showed regional warming at a rate of $0.204^{\circ} \mathrm{C}$ every $10 \mathrm{yr}$.
\end{abstract}

KEY WORDS: Air temperature $\cdot$ Precipitation $\cdot$ Soil aridity $\cdot$ Climate change

\section{INTRODUCTION}

Soil temperature reflects how climate may influence local subterranean ecological processes, especially the dynamics of biological reactions. Fluctuations in soil temperature illustrate the energy transfer processes through which ecosystem functions of the terrestrial environment are regulated (Peters-Lidard et al. 1998, Qi \& Song 2003, Portmann et al. 2009). Plant growth and seed germination, respiration of soil biota, and carbon sequestration and mineralization are all temperature dependent (Seyfried et al. 2001, Brooks et al. 2005). Changes in soil temperature determine the rate of biogeochemical processes in soils and carbon balances in terrestrial ecosystems (Trumbore et al. 1996, Goulden et al. 1998, Schimel et al. 2004, Zhang et al. 2005). Soil temperature variability is better modulated and less susceptible to wild fluctuations than atmos- pheric temperature, as soil has a greater thermal capacity than air. Soil is, therefore, a more stable parameter for reflecting climate change and its ecological impacts than ambient temperature. However, it may be more problematic to delineate the spatial distribution of soil temperatures across a region because it is measured at fewer places and less frequently than are ambient temperatures. Even with the advent of real-time sensors and data loggers, networks for direct measurements have been cumbersome to set up. For this reason, soil temperatures have most commonly been estimated (Brown et al. 2000, Kang et al. 2000, Zhu \& Liang 2005, Chudinova et al. 2006, Gao et al. 2007).

It is common practice to infer soil temperatures from ambient temperatures, which are generally measured at more locations and for which records have been maintained over much longer periods of time (Watson 1980, Manrique 1988, Gonzalez-Rouco et al. 2003, Zhu 
\& Liang 2005, Chudinova et al. 2006, Gao et al. 2007). Soil temperature correlates with the respective air temperature because both are governed by the energy balance at the atmosphere-ground interface. The scope of research in this area is wide. Hasfurther \& Burman (1974) used daily air temperature as a driving variable to predict daily soil temperature by a mathematical model. Persaud \& Chang (1983) decomposed a 2 yr daily soil temperature time series and its corresponding air temperature time series into deterministic and stochastic components. A transfer function was derived, based on Box-Jenkins transfer function modeling techniques, to estimate the soil temperature from the air temperature. Bocock et al. (1977) reviewed linear regression, multiple regression, and harmonic analysis methods of estimating soil temperature from air temperature and other climatic variables. Toy et al. (1978) used monthly mean air temperature to predict monthly soil temperature at continental scales. Mahrer (1980) developed a numerical model to predict the soil temperatures of bare and mulched surfaces using standard meteorological data and the physical characteristics of the soil. Zheng et al. (1993) estimated the daily soil temperature using daily air temperature and precipitation data. Kang et al. (2000) developed a hybrid soil temperature model to predict the spatial patterns of daily soil temperature in a forested landscape by incorporating the effects of topography, canopy, and ground litter on heat transfer.

Besides the empirical correlations between soil temperature and easily acquired climate variables, soil temperature might be estimated by soil heat flow and energy balance (Kang et al. 2000). The process-based models provide conceptually rigorous procedures to estimate soil temperature at small temporal and spatial scales, but the models are computationally demanding and the parameters are extensive. As such they may not be practical for estimating soil temperature at regional, continental, and global scales, as the model parameters required vary across the landscape. Empirical approaches based on regression models, such as that by Zheng et al. (1993), require only a few variables, i.e. air temperature and the leaf area index (LAI). However, they may only be valid for the areas in which the model parameters were calibrated.

Hansen et al. (2006) and Seinfeld (2008) have reported that, during the last century, the Earth's atmospheric temperature has risen by approximately $0.8^{\circ} \mathrm{C}$. To what extent has the soil temperature changed over the same period of time? In desert regions, vegetation is sparse and much of the soil is exposed to solar radiation. Soil temperature in the desert is, therefore, especially susceptible to the influence of climate. In a changing climate, desert soil temperatures can also be expected to change, potentially altering terrestrial eco- systems. We hypothesize that desert soil temperatures are influenced by regional climate factors and that soil temperature is a reliable indicator of the local responses of the environment to global climate change. The work presented here is based on a long-term soil temperature monitoring dataset for the Mojave Desert, located in the southwestern United States. From the data, an empirical soil temperature estimation model for the Mojave Desert was built and validated. Soil temperature was back-casted according to the ambient temperature and precipitation records of the past $100 \mathrm{yr}$ to reconstruct the long-term soil temperature changes in the Mojave Desert.

\section{MATERIALS AND METHODS}

\subsection{Study area}

The Mojave Desert, covering an area of $152000 \mathrm{~km}^{2}$ in southeastern California, southern Nevada, southwest Utah, and northwestern Arizona, is geologically complex and topographically diverse. Elevations in the region range from below sea level at Badwater $\left(36^{\circ} 13.96^{\prime} \mathrm{N}, 116^{\circ} 46.70^{\prime} \mathrm{W}\right)$ in Death Valley $(-86 \mathrm{~m})$ to Charleston Peak (3633 m; 36 $\left.16.33^{\prime} \mathrm{N}, 115^{\circ} 41.70^{\prime} \mathrm{W}\right)$ northwest of Las Vegas. Except for the mountains, the desert floors are wide and rolling, with gentle gradients slopes and a sparse coverage of diverse vegetation. In the Mojave Desert, summers are long and hot. Daily temperature extremes vary from -9 to $+57^{\circ} \mathrm{C}$ across the region (Bunn et al. 2007). While there are short periods of freezing temperatures at high elevations during the winter, the nighttime minimum air temperatures on the desert floor seldom drop below $0^{\circ} \mathrm{C}$. The average annual precipitation in the Mojave Desert is $<150 \mathrm{~mm}$, with many areas receiving $\ll 100 \mathrm{~mm}$. Most of the precipitation occurs in the winter.

\subsection{Data collection}

The mean annual soil temperatures at $50 \mathrm{~cm}$ depth were measured at 75 monitoring sites throughout the Mojave Desert. Elevations of the monitoring sites varied from -59 to $2363 \mathrm{~m}$. One-half of the monitoring sites had north-facing aspects, while the remainder had south-facing aspects. Collection of data started in 1982, 1983, or 1984 and ended in 1999 or 2000, depending on the site. The soil temperature was measured based on the Pallmann method (Pallmann et al. 1940, Norton \& Friedman 1981). Details of soil temperature measurements and monitoring sites can be found in Bai et al. (2010). 
To delineate the interrelationships between soil temperature and climate, the air temperature, precipitation, and evaporation records of 18 weather stations that were located near soil temperature monitoring sites and at elevations similar to those of corresponding monitoring sites (Fig. 1) were obtained from the Western Regional Climate Center (www.wrcc.dri.edu). The daily air temperature data were averaged year by year to obtain the mean annual air temperature. The annual precipitation and evaporation values were obtained by summing the daily data year by year. When there were 5 or more missing data in any single month, the data of that year were not included. In total, 190 paired mean annual air temperatures (MAAT), and the corresponding precipitation and evaporation data, were assembled and used to build and validate the soil temperature predictive model.

To back-cast changes in soil temperature from the climatic conditions encountered in the past century, historical records of air temperature and precipitation were retrieved from 67 weather stations throughout the Mojave Desert region. Similarly, when 5 or more data were missing in any single month, the data for that year were not included. The final output provided the mean annual air temperature and precipitation of the Mojave Desert from 1904 to 2008. The data were used to reconstitute the mean annual soil temperatures (MAST) of the corresponding years.

\subsection{Data analysis}

A multiple linear regression analysis was conducted to link the spatial variation of soil temperature with other climatic factors, including air temperature, precipitation, and evaporation. The multiple linear regression analysis was carried out with SAS software (Version 9.0). The database was split into a model-building set and a validation set.

The degree of soil dryness was calculated based on the index of aridity, proposed by UNEP (1992), which is given as:

$$
\mathrm{AI}=\frac{P}{\mathrm{PET}}
$$

where AI refers to the aridity index, PET represents the potential evapo-transpiration derived from the pan evaporation, and $P$ is the average annual precipitation.
Soil temperature measurement sites and their nearest weather stations



collection of data

\section{RESULTS AND DISCUSSION}

\subsection{Correlations between soil temperature and other climate factors}

Paired data obtained from measurements at the monitoring sites and their corresponding nearby weather stations were used to examine the correlations between soil temperature and other climatic factors (Fig. 2). Linear regression analyses were conducted to illustrate the correlations between MAST and 3 climatic factors, including MAAT, annual precipitation, and annual evaporation (Table 1). There is a significant linear regression between MAST and MAAT at $\mathrm{p}<0.05$. The standard error of the slope coefficient was $<10 \%$. The linear regression explained around $90 \%$ of the variance of MAST versus MAAT (i.e. $\mathrm{R}^{2}=$ 0.90). As indicated by the slope coefficient, which is very close to 1 , the soil temperature of the Mojave Desert rises and falls in parallel with the air temperature. On average, the MAST was about $5^{\circ} \mathrm{C}$ higher than the MAAT in the region (intercept of the linear regression equals $4.95^{\circ} \mathrm{C}$ ). In an arid desert environment, the ground surface energy balance is mainly governed by the sensible and infrared heat flux. The sensible and radiation heat transfers require a relatively large temperature difference. As a result, the soil temperature in the desert tends to be much warmer than the ambient air temperature. 

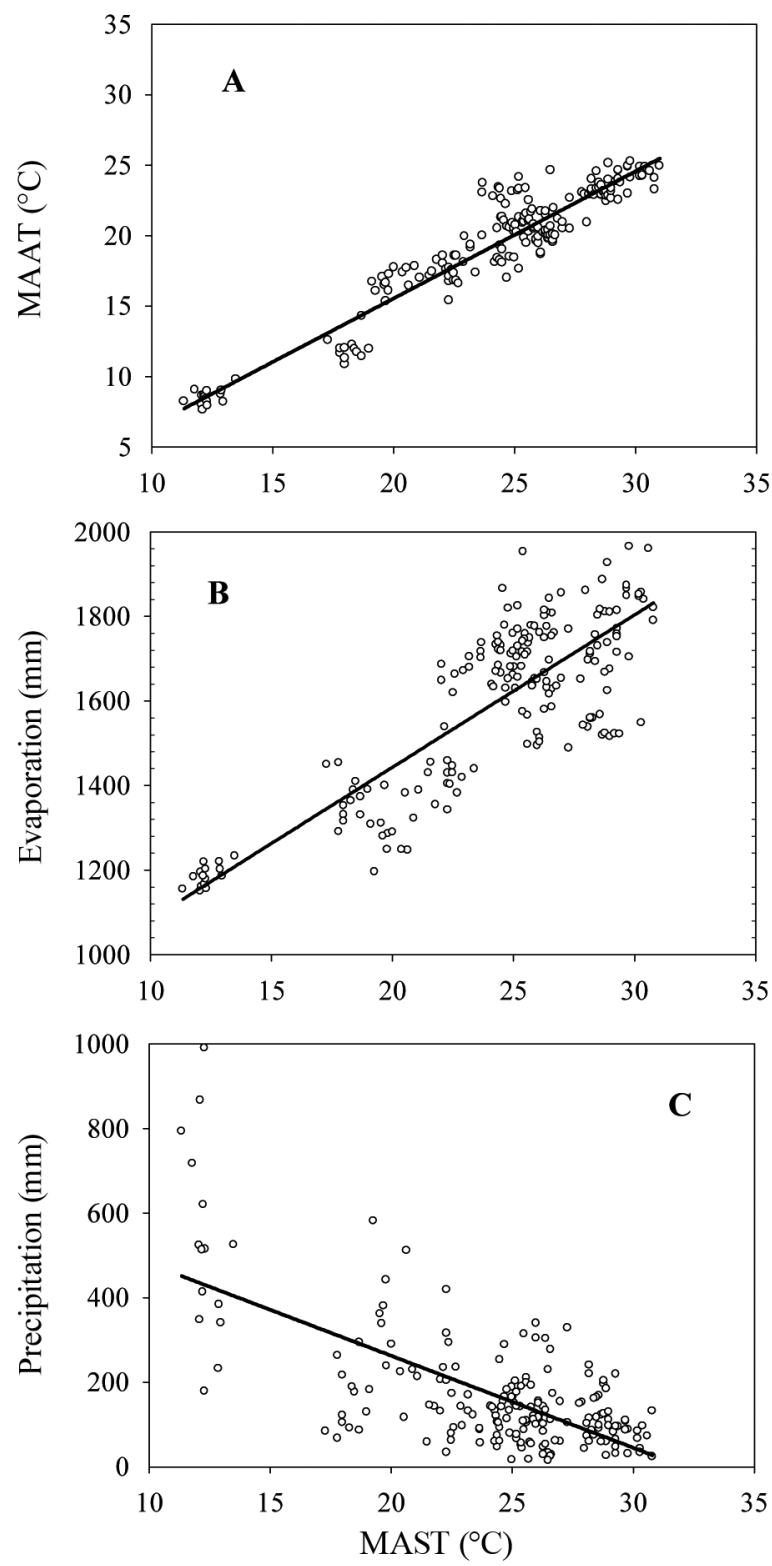

Fig. 2. Linear regression between mean annual soil temperature (MAST) and (A) mean annual air temperature (MAAT), (B) annual potential evaporation, and (C) annual precipitation in the Mojave Desert
There is also a significant linear relationship between mean annual evaporation and annual soil temperature $(p<0.05)$. The standard error of the slope coefficient was quite small, and the slope coefficient was significantly different from zero. The linear regression explained around $68 \%$ of the variation of annual evaporation versus MAST (i.e. $\mathrm{R}^{2}=0.68$ ). Due to high air temperature and low relative humidity, the annual pan evaporation in the Mojave Desert region is high, ranging from around 1000 to $>3000 \mathrm{~mm}$. Vast amounts of energy are needed for water evaporation. Therefore, a high evaporation rate is generally associated with high air or soil temperature.

The annual precipitation was negatively correlated with the mean annual soil temperature $\left(R^{2}=0.45\right)$, and the regression was significant at $\mathrm{p}<0.05$ (Fig. 2C). The average annual precipitation of the Mojave Desert is approximately $150 \mathrm{~mm}$. At high elevations, however, the annual precipitation may reach $>400 \mathrm{~mm}$. Precipitation increases the soil moisture content, which, in turn, may significantly impact the exchange of heat energy between the land surface and atmosphere. The heat capacity of water is about 5 times that of mineral soil particles. Moist soils would absorb more heat than dry soils to achieve the same level of temperature rise. Besides increasing the soil's thermal capacity, soil moisture also increases soil heat conductivity and reduces soil albedo. Soil moisture content is mainly dependent on inputs through precipitation and outputs through evaporation and plant transpiration. Therefore, it is expected that the regional variations in soil temperature are affected by precipitation and evaporation.

Fig. 3 illustrates the correlation between mean annual soil temperature and the aridity index (AI) in the Mojave Desert. As annual potential evaporation is considerably higher than annual precipitation, the soils of the Mojave Desert are very dry. Most of the region is considered either arid $(0.05<\mathrm{AI}<0.20)$ or hyper-arid $(\mathrm{AI}<0.05)$. The aridity index decreases exponentially as the soil temperature increases $\left(R^{2}=0.57\right)$, and the regression is significant at $\mathrm{p}<0.05$.
Table 1. Linear regression, $Y=a+b X$, between the mean annual soil temperature $(Y)$ and mean annual air temperature (MAAT), annual precipitation, and annual evaporation $(X)$. SE: standard error of the estimate

\begin{tabular}{|lcccccccc|}
\hline \multirow{2}{*}{ Variable } & \multicolumn{4}{c}{ ANOVA } & \multicolumn{4}{c|}{ Coefficients of regression equation } \\
\cline { 2 - 8 } & $\mathrm{R}^{2}$ & $F$ & $\mathrm{p}$ & Y-intercept & SE & Slope & SE \\
\hline \multirow{2}{*}{ MAAT } & 0.90 & 1761 & $<0.0001$ & 4.95 & 0.48 & 0.996 & 0.024 \\
Evaporation & 0.69 & 412 & $<0.0001$ & 722 & 43.7 & 36.0 & 1.78 \\
Precipitation & 0.45 & 155 & $<0.0001$ & 27.7 & 0.38 & -0.021 & 0.002 \\
\hline
\end{tabular}

\subsection{Predicting the variation in soil temperature}

The soil temperature and climatic data were evenly split into the modelbuilding and validation datasets. The regression analysis based on the modelbuilding dataset showed that multiple regression of MAST was significant with all 3 climatic factors, i.e. MAAT, annual precipitation, and annual pan 
evaporation $(\mathrm{p}<0.05)$. However, the variance inflation factor for MAAT and annual evaporation was large, indicating that multi-co-linearity was present among these 2 variables. Given that MAAT was better correlated with MAST than with annual evaporation, annual evaporation was deleted from the multivariate linear analysis. No clear pattern was observed in the plot of residuals against predicted values. Box-Cox transformations analysis showed that no transformation of data was needed, and, based on the normal Q-Q plot, there was no clear departure from normality.

The results of model selection based on different criteria are summarized in Table 2. In the F-test-based stepwise selection process, MAAT was first chosen as the variable predictor, and then precipitation was included. The $\mathrm{R}^{2}$-values of the resulting equations were not significantly improved with the addition of precipitation. However, the Mallows' Cp-value was significantly smaller and equaled the perfect value of 3. Mal-



Fig. 3. Linear regression between mean annual soil temperature and the annual aridity index (ratio of annual evaporation to potential precipitation) in the Mojave Desert lows' $\mathrm{Cp}$ is a gauge of the size of the bias introduced into the estimate of the dependent variable when the independent variables are omitted from the regression equation. The results indicated that, while the variation of soil temperature in the Mojave Desert was dominated by the variation of air temperature, the impacts of precipitation could not be omitted. The results of Akaike's information criterion (AIC) and Schwartz's Bayesian information criterion (BIC), which indicate how well the selected model fit the data, also showed that the model's predictive capability was improved by inclusion of precipitation in the model. The best model based on the model-building dataset was:

$$
\begin{gathered}
\operatorname{MAST}\left({ }^{\circ} \mathrm{C}\right)=7.05+0.916 \times \\
\operatorname{MAAT}\left({ }^{\circ} \mathrm{C}\right)-0.0031 \times P\left(\mathrm{~mm} \mathrm{yr}^{-1}\right)
\end{gathered}
$$

The model based on the validation dataset was very similar to that based on the model-building dataset (Table 3). The mean squared error $\left(\mathrm{MSE}=1.97^{\circ} \mathrm{C}\right)$ of the predicted validation dataset obtained through Eq. (2) did not differ significantly from the actual $\operatorname{MSE}\left(2.37^{\circ} \mathrm{C}\right)$ of the model validation dataset. For the validation dataset, the predicted MAST agreed with the observed MAST. The plot of predicted versus observed MAST values showed the data points were distributed very close to the $y=x$ line (Fig. $4 ; R^{2}=0.98$ ), and the linear regression was significant at $\mathrm{p}<0.05$. The regression equation derived from the modelbuilding dataset was a reasonable and valid indicator of the predictive ability of the fitted regression model (Eq. 2). To improve the accuracy of Eq. (2), the entire MAST dataset was employed to refine the model, and the final outcome was:

$$
\begin{gathered}
\operatorname{MAST}\left({ }^{\circ} \mathrm{C}\right)=6.84+0.925 \times \\
\operatorname{MAAT}\left({ }^{\circ} \mathrm{C}\right)-0.0031 \times P\left(\mathrm{~mm} \mathrm{yr}^{-1}\right)
\end{gathered}
$$

Table 2. Model selection results based on different criteria

\begin{tabular}{|ll|}
\hline Criterion & Variable predictors selected in the best 3 models \\
\hline F-test-based & Air temperature $\left(\mathrm{R}^{2}=0.8866, \mathrm{Cp}=6.86\right)$ \\
stepwise selection & Precipitation $\left(\mathrm{R}^{2}=0.8933, \mathrm{Cp}=3\right)$ \\
Akaike's & Air temperature and precipitation $(\mathrm{AIC}=85.03)$ \\
information & Air temperature $(\mathrm{AIC}=88.89)$ \\
criterion (AIC) & Precipitation (AIC $=236.04)$ \\
Schwartz's & Air temperature and precipitation $(\mathrm{BIC}=92.69)$ \\
Bayesian criterion & Air temperature $(\mathrm{BIC}=94.00)$ \\
information $(\mathrm{BIC})$ & Precipitation $(\mathrm{BIC}=241.15)$ \\
Mallows' Cp & Air temperature and precipitation $(\mathrm{Cp}=3)$ \\
& Air temperature $(\mathrm{Cp}=6.86)$ \\
Adjusted $\mathrm{R}^{2}$ & Precipitation $(\mathrm{Cp}=369.57)$ \\
& Air temperature and precipitation $\left(\mathrm{adj} . \mathrm{R}^{2}=0.8933\right)$ \\
& Air temperature $\left(\mathrm{adj} . \mathrm{R}^{2}=0.8866\right)$ \\
& Precipitation (adj. $\left.\mathrm{R}^{2}=0.4661\right)$ \\
\hline
\end{tabular}

\subsection{Extrapolating the long-term variation of soil temperature}

Fig. 5 illustrates the temporal changes of mean annual air temperature in the Mojave Desert from 1904 to 2008. There were 3 distinctive periods. The mean annual air temperatures before 1930 were generally below the century average (Fig. 5). From then on, the mean annual air temperature stayed mostly above the century average. While there was a slightly decreasing trend of MAAT from 1930 to 1970, the decrease was statistically 
Table 3. Comparison of regression results based on the modelbuilding and validation datasets

\begin{tabular}{|lccrcr|}
\hline Variable & $\begin{array}{c}\text { Parameter } \\
\text { estimate }\end{array}$ & $\mathrm{SE}$ & $t$ & $\mathrm{p}$ \\
\hline Build-up dataset & & & & \\
Intercept & 7.05 & 1.09 & 6.45 & $<0.0001$ \\
Air temperature & 0.92 & 0.048 & 19.20 & $<0.0001$ \\
Precipitation & -0.0031 & 0.0013 & -2.42 & 0.0175 \\
Validation dataset & & & & \\
Intercept & 6.68 & 0.98 & 6.81 & $<0.0001$ \\
Air temperature & 0.93 & 0.042 & 22.40 & $<0.0001$ \\
Precipitation & -0.0031 & 0.0014 & -2.29 & 0.0246 \\
\hline
\end{tabular}

insignificant. From 1970, there was a rapid increase of MAAT, at an estimated rate of $0.404 \pm 0.074^{\circ} \mathrm{C}$ every 10 yr. Overall, there had been a warming trend in the Mojave Desert from 1904 to 2008, with temperatures rising at an estimated rate of $0.206 \pm 0.026^{\circ} \mathrm{C}$ every 10 yr. Cumulatively, air temperature in the Mojave Desert rose by approximately $2{ }^{\circ} \mathrm{C}$ during the last century (Fig. 5), considerably more than the estimated rise in global ambient temperatures over the same period of time (Hansen et al. 2006, Seinfeld 2008). The pattern of change in air temperature observed in the Mojave Desert, however, was in agreement with the global trend reported by Hansen et al. (2006) that showed 2 apparent warming periods, from 1910 to 1945 and from 1976 onwards.

Fig. 6 illustrates the temporal changes in annual precipitation in the Mojave Desert from 1904 to 2008. In the past century, there were distinctive droughts and dry conditions as well as wet episodes. Two multidecadal precipitation regimes were apparent, depicting the mid-century dry spell from 1942 to 1977 and the drought in the late 1980s. The linear regression of

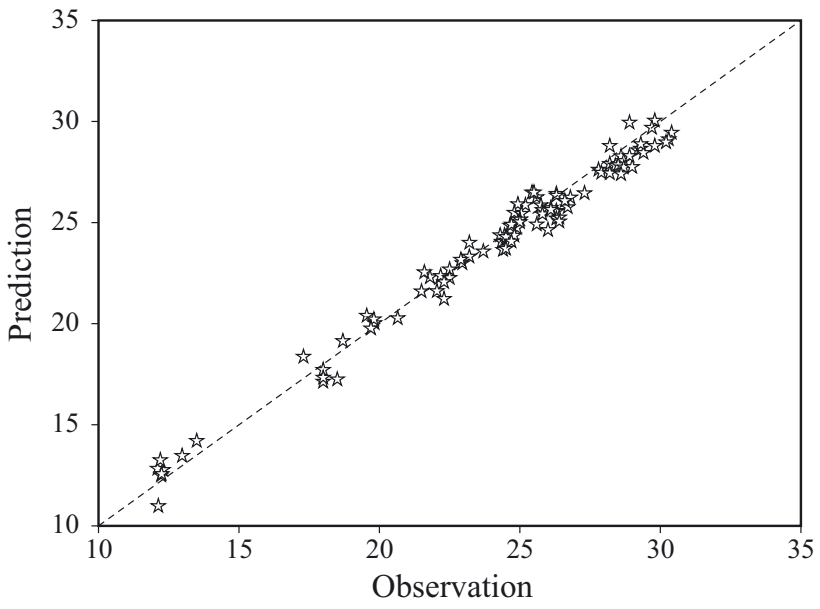

Fig. 4. Observed versus predicted mean annual soil temperature of the model-validation dataset

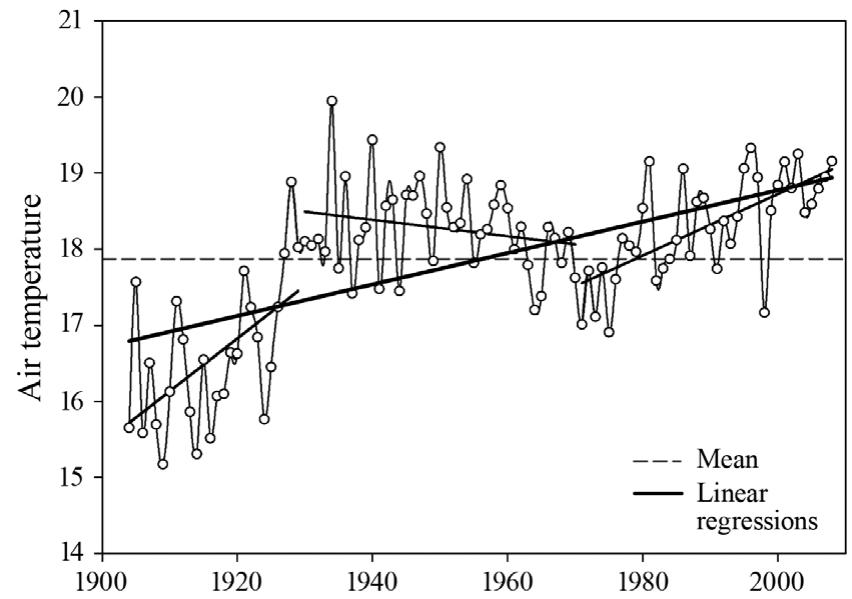

Fig. 5. Time series of mean annual air temperature from 1904 to 2008 , constructed from weather station data

annual precipitation versus time exhibited a negative slope coefficient, suggesting that annual precipitation was inclined to decrease with time. However, the slope coefficient was not significantly different from zero, indicating that the variation in annual precipitation was insignificant ( $p>0.05)$ during the study period.

The long-term variation of mean annual soil temperature in the past century may be back-casted from the mean annual air temperature and annual precipitation shown in Figs. $5 \& 6$, respectively, by the predictive model of Eq. (3). Fig. 7 illustrates the temporal changes in the mean annual soil temperature of the Mojave Desert from 1904 to 2008. As the temporal variation of precipitation was not significant during the last century, the mean annual soil temperature changed according to fluctuations in the mean annual air temperature in the Mojave Desert, with a warming rate of $0.204 \pm 0.027^{\circ} \mathrm{C}$ every $10 \mathrm{yr}$. Cumulatively, soil temperature across the region has increased about $2^{\circ} \mathrm{C}$ in the

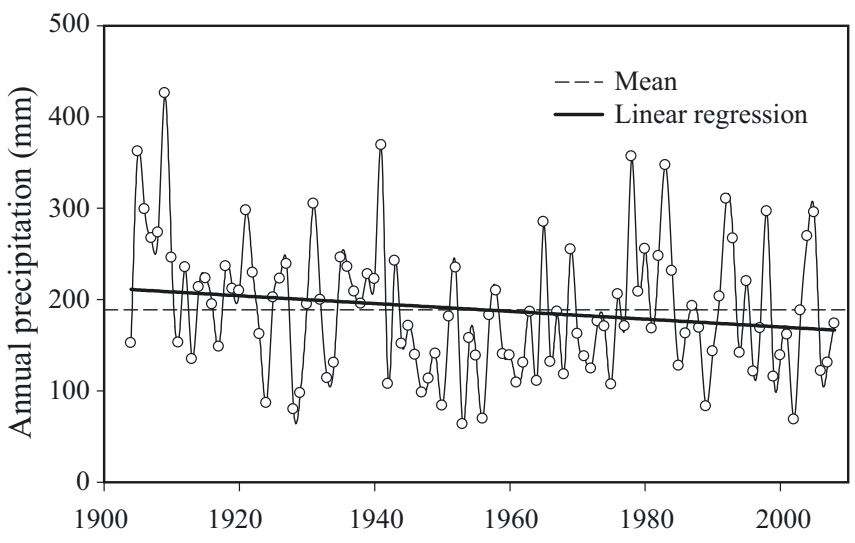

Fig. 6. Time series of annual precipitation from 1904 to 2008, constructed from weather station data 


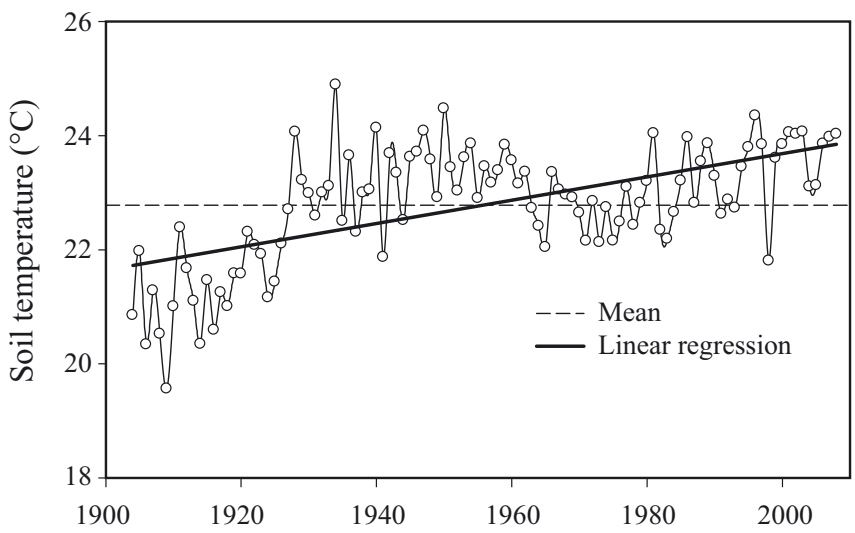

Fig. 7. Time series of mean annual soil temperature in the Mojave Desert from 1904 to 2008, based on outcomes of the soil temperature predictive model involving mean annual air temperature and annual precipitation

last century. The results indicated that soil temperatures measured at $50 \mathrm{~cm}$ depth reflect regional climatic change in a similar manner as ambient temperature measurements. Since the variation of soil temperature integrates both the variation of air temperature and precipitation, it is a suitable indicator for monitoring both local climate and corresponding changes in the terrestrial ecosystem.

\section{CONCLUSIONS}

In the Mojave Desert, soil temperature varies in response to air temperature and is greatly affected by soil moisture content, which is mainly dependent on precipitation and evaporation. There was a negative linear relationship between soil temperature and precipitation, while there was a positive linear relationship between soil temperature and evaporation. Soil aridity, defined by the ratio of potential annual evapotranspiration to average annual precipitation, increases exponentially with soil temperature. The MAST of the Mojave Desert is best predicted by MAAT and annual precipitation as shown in Eq. (3).

The long-term climatic records from weather stations throughout the Mojave Desert showed that there have been 2 distinctive warming periods in the past century, which is in agreement with the pattern of global climate change reported elsewhere. Both MAAT and MAST have increased by approximately $2^{\circ} \mathrm{C}$ in the last century, whereas annual precipitation has not been significantly affected by this warming trend.

Soil temperature, incorporating the variations of both air temperature and precipitation, is an appropriate parameter for monitoring the long-term regional changes in climate and in terrestrial ecosystems.

\section{LITERATURE CITED}

Bai YY, Scott TA, Chen WP, Chang AC (2010) Evaluating methods for measuring the mean soil temperature. Geoderma 157:222-227

Bocock KL, Jeffers JNR, Lindley DK, Adamson JK, Gill CA (1977) Estimating woodland soil temperatures from air temperature and other climatic variables. Agric Meteorol 18:351-372

Brooks PD, McKnight D, Elder KK (2005) Carbon limitation of soil respiration under winter snowpacks: potential feedbacks between growing season and winter carbon fluxes. Glob Change Biol 11:231-238

Brown SE, Pregitzer KS, Reed DD, Burton AJ (2000) Predicting daily mean soil temperature from daily mean air temperature in four northern hardwood forest stands. For Sci 46:297-301

Bunn D, Mummert A, Hoshovsky M, Gilardi K, Shanks S (2007) Mojave desert region, Chap 7. California wildlife: conservation challenges. California's Wildlife Action Plan prepared by the UC Davis Wildlife Health Center for the California Department of Fish and Game, Davis, CA, p 97-127

Chudinova SM, Frauenfeld OW, Barry RG, Zhang TJ, Sorokovikov VA (2006) Relationship between air and soil temperature trends and periodicities in the permafrost regions of Russia. J Geophys Res 111(F2):F02008

Gao Z, Bian L, Hu Y, Wang L, Fan J (2007) Determination of soil temperature in an arid region. J Arid Environ 71:157-168

Gonzalez-Rouco F, von Storch H, Zorita E (2003) Deep soil temperature as proxy for surface air-temperature in a coupled model simulation of the last thousand years. Geophys Res Lett 30:2116

Goulden ML, Wofsy SC, Harden JW, Trumbore SE and others (1998) Sensitivity of boreal forest carbon balance to soil thaw. Science 279:214-217

Hansen J, Sato M, Ruedy R, Lo K, Lea DN, Medina-Elizade M (2006) Global temperature change. Proc Natl Acad Sci USA 103:14288-14293

Hasfurther VR, Burman RD (1974) Soil temperature modeling using air temperature as a driving mechanism. Trans ASAE 16:78-81

Kang S, Kim S, Oh S, Lee D (2000) Predicting spatial and temporal patterns of soil temperature based on topography, surface cover and air temperature. For Ecol Manag 136: 173-184

Mahrer Y (1980) A numerical model for calculating the soil temperature regime under transparent polyethylene mulches. Agric Meteorol 22:227-234

Manrique LA (1988) Effects of rainfall and cover on soil temperatures of an isohyperthermic temperature regime, Panama. Geoderma 42:129-146

Norton DR, Friedman I (1981) Ground temperature measurements. I. Pallmann technique. Geological Survey Professional Paper 1203, US Government Printing Office, Washington, DC

Pallmann H, Eichenberger E, Hasler A (1940) Eine neue Methode der Temperaturmessung bei okologischen oder bodenkundlichen Untersuchungen. Ber Schweiz Bot Ges 50:337-362

Persaud N, Chang AC (1983) Estimating soil temperature by linear filtering of measured air temperature. Soil Sci Soc Am J 47:841-847

> Peters-Lidard CD, Blackburn E, Liang X, Wood EF (1998) The effect of soil thermal conductivity parameterization on surface energy fluxes and temperatures. J Atmos Sci 55: $1209-1224$ 
Portmann RW, Solomon S, Hegerl GC (2009) Spatial and seasonal patterns in climate change, temperatures, and precipitation across the United States. Proc Natl Acad Sci USA 106:7324-7329

Qi H, Song F (2003) A daily soil temperature dataset and soil temperature climatology of the contiguous United States. J Appl Meteorol 42:1139-1156

Schimel JP, Bilbrough C, Welker JA (2004) Increased snow depth affects microbial activity and nitrogen mineralization in two Arctic tundra communities. Soil Biol Biochem $36: 217-227$

Seinfeld J (2008) Climate change. Rev Chem Engin 24:1-65

Seyfried MS, Flerchinger GN, Murdock MD, Hanson CL, Van Vactor S (2001) Long-term soil temperature database, Reynolds Creek Experimental Watershed, Idaho, United States. Water Resour Res 37:2843-2846

Toy TJ, Kuhaida AJ, Munson BE (1978) The prediction of mean monthly soil temperature from mean monthly air

Editorial responsibility: Peter Gleckler,

Livermore, California, USA temperature. Soil Sci 126:181-189

> Trumbore SE, Chadwick OA, Amundson R (1996) Rapid exchange between soil carbon and atmospheric carbon dioxide driven by temperature change. Science 272:393-395

UNEP (United Nations Environment Program) (1992) World atlas of desertification. Edward Arnold, London

Watson CL (1980) Seasonal soil temperature regimes in south-eastern Australia. Aust J Soil Res 18:325-331

Zhang Y, Chen W, Smith SL, Riseborough DW, Cihlar J (2005) Soil temperature in Canada during the twentieth century: complex responses to atmospheric climate change. J Geophys Res 110:D03112 doi:10.1029/2004JD004910

Zheng D, Hunt ER, Running SW (1993) A daily soil temperature model based on air temperature and precipitation for continental applications. Clim Res 2:183-191

$>$ Zhu J, Liang XZ (2005) Regional climate model simulation of U.S. soil temperature and moisture during 1982-2002. J Geophys Res 110:D24110 doi:10.1029/2005JD006472

Submitted: January 8, 2010; Accepted: November 1, 2010 Proofs received from author(s): January 19, 2011 